\section{LANDSCAPE \\ AND \\ URBAN PLANNING}

Landscape and Urban Planning 78 (2006) 229-240
This article is also available online at: www.elsevier.com/locate/landurbplan

\title{
The economics of native plants in residential landscape designs
}

\author{
Gloria E. Helfand*, Joon Sik Park, Joan I. Nassauer, Sandra Kosek \\ School of Natural Resources and Environment, The University of Michigan, Dana Bldg., 440 Church St., \\ Ann Arbor, MI 48109-1041, USA
}

Received 23 August 2004; received in revised form 20 April 2005; accepted 16 August 2005

Available online 25 October 2005

\begin{abstract}
Yard-scale landscape designs can influence environmental quality through effects on habitat, stormwater runoff, and water quality. Native plant gardens may have ecological benefits, and previous research has shown that yards using these plants can be designed in ways that people find attractive. This study examines whether people are willing to pay more for more ecologically benign designs than for a lawn. A contingent choice survey was conducted in southeast Michigan in which people were presented with four different yard designs (three of which included native plants) in three different settings, with different monthly maintenance costs for each design. Respondents were asked to rank their choices of the yards while considering the maintenance costs they were presented. Results suggest that people are willing to pay more for well-designed yards including native plants than for lawns, and that their increased willingness to pay exceeds any increase in costs associated with the native plantings. These results should encourage homeowners, landscape designers, and the landscape plant industry to work with native plants. In this study, people were willing to pay more for designs that present gains for the environment, without government intervention and without social cost.
\end{abstract}

(C) 2005 Elsevier B.V. All rights reserved.

Keywords: Ecological design; Landscape architecture; Native plants; Economics; Contingent choice

\section{Introduction}

In parts of the world dominated by humans, landscape design can have significant environmental effects. The aggregate effects of private landscapes can influence habitat and water quality, among other environmental attributes. As a result, innovative landscapes

\footnotetext{
* Corresponding author. Tel.: +1 734764 6529; fax: +1 7349362195 .

E-mail address: ghelfand@umich.edu (G.E. Helfand).
}

that incorporate ecologically beneficial land cover patterns have been designed in multiple scales for private lands (Nassauer, 1993). The yard scale, the property occupied by a single residential dwelling, is relatively small, but a mosaic of environmentally beneficial yards can in the aggregate contribute to ecological health (Nassauer, 1997).

Currently, residential yards are primarily turf lawn. Lawns can contribute to environmental problems, including high fossil energy use, high chemical input use (such as pesticides, herbicides, and fertilizers), 
health problems related to those chemicals, solid waste, high water usage, water pollution, and decreased biodiversity (Bormann et al., 1993, pp. 86-117; Templeton et al., 1999). Alternative yard designs using native plants may require less external inputs and support more biodiversity (Northeastern Illinois Planning Commission, 1998; Bormann et al., 1993; Diekelmann and Schuster, 2002, pp. 1-8). On the other hand, ecologically healthy landscapes are not always considered attractive. If alternative landscape designs do not satisfy people's views of attractive landscapes, they will not install or support them.

Nassauer (1993) has found that yards incorporating native plants can be as attractive, or even more attractive, to homeowners as conventional yards that do not include native plants. A next step in this research is to evaluate how people respond to these landscapes when faced with them in a market situation. What people consider attractive may not translate into what they would be willing to purchase, because the prices of the alternatives will affect the decision. Incorporating prices into landscape perception research sets up a linkage among ecologically oriented function, aesthetic design, and economic choice. If consumers are willing to purchase these designs at prices that designers must charge to run a viable business, then environmental gains can be achieved through private markets.

If the environmental gains from these landscapes are expected to be significant, then the economics of these designs has implications for public versus private sector roles in achieving these gains. If ecologically beneficial landscapes are economically viable at their likely costs, then private markets could be expected to offer these designs. In that case, it is possible for some environmental improvements to be achieved through the private sector, without a need for public sector intervention. Indeed, ecologically beneficial landscapes could be a "win-win" situation: both homeowners and landscape providers willingly install these designs, and the environment is improved with no additional public or private actions. If, on the other hand, people's willingness to pay for these landscapes is less than their market costs, then environmental improvements either have to come from other sources, or they must be made at net cost to homeowners, to landscape providers, or some other source.

This study employs a valuation method that examines people's willingness to pay for ecologically beneficial landscape designs. This method, known as contingent choice, uses survey responses to estimate people's values for goods for which a market does not (currently) exist. Respondents are asked to rank their preferences for goods with different attributes and prices-in this case, yards with different levels of native plantings. Examining people's choices when attributes and prices are varied permits estimation of the tradeoffs that people see between attributes and prices. That tradeoff becomes a measure of a person's willingness to pay for a specified change in the attribute.

This paper will first provide theoretical background for the valuation exercise and the econometric model. A description of the survey design, survey area, data collection, and econometric model used for the study will follow. The next section will discuss the results, followed by the conclusion.

\section{Measurement of willingness to pay in theory and practice}

When economists measure the value of a good to someone, the price paid when a purchase is made is only a minimum estimate of that value; the consumer was clearly willing to pay the market price, but she might have been willing to pay even more to have the good. Instead of using price as a measure of the value of a good to a consumer, economists seek to estimate consumers' willingness to pay (WTP), the maximum amount that a person would pay to obtain a good. The difference between WTP and the actual purchase price is pure gain to the consumer and is known as consumer surplus. For marketed goods, WTP can be estimated from the demand curve for a good (the relationship between quantity purchased and the price at which that quantity is purchased), since the demand curve measures how much consumers purchase as the market price changes.

For nonmarketed goods - either goods that are not yet on the market (such as new products) or goods not traded in markets (such as most environmental goods) - it is not possible to estimate the demand curve based on direct market behavior. It might nevertheless be possible to estimate this demand, either by "revealed preference" methods that exploit the relationship of the good to a privately marketed good (such as estimating demand for neighborhood parks by looking at 
property values near the parks compared to those further away), or by "stated preference" methods, asking people about their behavior in a hypothetical scenario involving the good (Freeman, 1993). ${ }^{1}$ Because stated preference approaches are based on people's responses to hypothetical scenarios, it has been criticized as not truly capturing how people would behave when actually faced with the tradeoffs described (e.g., Diamond and Hausman, 1994). Some literature indicates that people's stated willingness to pay exceeds their actual willingness to pay (in situations where actual payments are made) by a factor as much as 10 , with the ratio between hypothetical and actual payments appearing to be good-specific (List and Shogren, 2002). Others have found cases, though, where the results of a stated preference study are close to those of a revealed preference analysis (Loomis and Helfand, 2001, Chapter 9). "Hypothetical bias," the potential exaggeration of willingness to pay in hypothetical scenarios, is an active subject of research in environmental economics (e.g., List, 2001; List et al., 2004).

Contingent choice was used here for several reasons. First, because the landscape designs examined here are not in common use, there are only limited possibilities for doing a revealed preference analysis. Secondly, the stated preference approach allows greater control over the scenarios that respondents face; actual use of alternative landscape designs is likely to vary tremendously.

In a contingent choice experiment, a consumer is presented with two or more hypothetical options that vary in their attributes. In the study here, for example, a consumer is faced with the choice between 1 yard with a traditional lawn and 3 yards with different proportions of prairie garden, each with a different price for purchase and maintenance. If the consumer chooses a higher priced option, it is clear that, not only does she prefer that option, but she is willing to give up other goods (through paying a higher price) to get it.

The theory underlying this experiment states that a person will rank the options according to the utility that each option provides to her. In other words, the utility associated with the highest ranked choice is higher than the utility of the second-ranked choice, which is ranked higher than the utility of the third-ranked choice, and

\footnotetext{
${ }^{1}$ Stated preference methods may also be used in situations where a market for the good exists, or where revealed preference methods can be used for related markets, to assess the reliability of the method.
}

so forth. The attributes and price of the good, as well as a person's characteristics, influence that decision.

Let $V_{i h}$ be the maximum utility of individual $i$ associated with alternative $h$, with a total of $H$ alternatives (that is, $V_{i h}$ is the indirect utility function ${ }^{2}$ ). The indirect utility $V_{i h}$ associated with choice $h$ depends on the levels of environmental quality $\left(E_{h}\right)$, the cost of $h$ $\left(C_{h}\right)$, individual income $\left(Y_{i}\right)$, and personal characteristics $\left(S_{i}\right)$. In general form, this equation may be written as:

$U_{i h}=V_{i h}\left(E_{h}, Y_{i}-C_{h}, S_{i}\right)$

For the work presented here, a linear indirect utility function is assumed:

$U_{i h}=\beta_{0}+\beta_{1} E_{h}+\beta_{2}\left(C_{h}-Y_{i}\right)+\beta_{3} S_{i}$

(Cost less income is used in this formulation to match the actual empirical specification, where cost of the alternative enters as a positive number in the equation.)

Willingness to pay (WTP) for one alternative compared to another is defined as the difference in income (the amount someone would be willing to pay) that would lead to constant utility between the two choices, since an individual should be indifferent between two alternatives that provide the same level of utility. For example, suppose that person $i$ with the linear indirect utility function in (2) faces a choice between alternatives $A$ and $B$. Since WTP for alternative $B$ compared to alternative $A$ is defined as the change in cost $\left(C_{A}-C_{B}=\Delta C\right)$ for a change in environmental quality $\left(E_{A}-E_{B}=\Delta E\right)$ required to make $i$ indifferent between the two, then

$$
\begin{aligned}
U_{i A}= & \beta_{0}+\beta_{1} E_{A}+\beta_{2}\left(C_{A}-Y_{i}\right)+\beta_{3} S_{i}=U_{i B} \\
& =\beta_{0}+\beta_{1} E_{B}+\beta_{2}\left(C_{B}-Y_{i}\right)+\beta_{3} S_{i}
\end{aligned}
$$

which, after some rearrangement, produces $\Delta C / \Delta E=-\beta_{1} / \beta_{2}$. Any factors that are identical between the two equations, such as the intercept term and individual characteristics in the above linear formulation, do not affect WTP, since they drop out of the calculation when the utilities are equated.

\footnotetext{
2 The indirect utility function is derived from maximizing a utility function subject to a budget constraint. The resulting demand decisions, when substituted back into the original utility function, provide a monetary measure of utility that is a function of the prices of goods, income, personal characteristics, and attributes of the goods.
} 
Remaining for the calculation are differences in environmental quality between the alternatives, and differences in the costs of the alternatives.

This calculation can include individual characteristics and other demographic variables if they are interacted with cost or other choice-specific variables (Lareau and Rae, 1989). For instance, in the application presented here, variations on the following specification are used:

$$
\begin{aligned}
U_{i h}= & \beta_{0}+\beta_{1} E_{h}+\beta_{2} C_{h}+\beta_{3} \frac{C_{h}}{Y_{i}} \\
& +\beta_{4} S_{i} E_{h}+\beta_{5} S_{i} C_{h}
\end{aligned}
$$

Once again, WTP is $\Delta C / \Delta E$, but now the specific form is more complex:

$$
\frac{\Delta C}{\Delta E}=\frac{-\left(\beta_{1}+\beta_{4} S_{i}\right)}{\left[\beta_{2}+\beta_{3} / Y_{i}+\beta_{5} S_{i}\right]}
$$

In the study here, respondents were asked to rank four choices (the traditional yard and three alternative designs) with different costs per month associated with each. The parameters of the indirect utility function can be estimated from the rankings that people give the alternatives. If the indirect utility function $U_{i h}$ and thus the choices associated with it have some error associated with it, then, under the assumptions that error terms are independently and identically distributed with an extreme-value distribution, the probability of a specific ranking of choices 1 through $H$ occurring can be calculated as (Beggs et al., 1981):

$$
\begin{gathered}
\operatorname{Prob}\left[U_{i 1}>U_{i 2}>\cdots>U_{i H}\right] \\
=\prod_{h=1}^{H}\left\{\frac{\exp \left(V_{i h}\right)}{\left[\sum_{j=h}^{H} \exp \left(V_{i j}\right)\right]}\right\}
\end{gathered}
$$

For estimating the parameters (the $\beta \mathrm{s}$ ins the above equations), the rank-ordered logit model, an extension of multinomial logit for ranked data, is used to estimate the parameters that maximize the likelihood of the ranking the respondents choose. Logit models are one form of limited dependent variable model-that is, a model where the dependent variable is a discrete choice rather than a continuous variable. Multinomial logit estimates the likelihood that an individual will choose one of several choices, but it does not take into account the rankings of choices other than the first: it would be known, for instance, if $U_{i 1}>U_{i K}$, where $K$ represents all choices other than choice 1, but there is no information about the relative rankings of choices other than choice 1: that is, it does not consider whether choice 2 is preferred to choice 3 . In contrast, the rankordered logit model incorporates the hierarchy of utility from all choices.

The rank-ordered logit model was developed by Beggs et al. (1981) to estimate the potential demand for electric cars. Lareau and Rae (1989) extended it to incorporate characteristic and demographic variables in their study of WTP for diesel odor reduction. Other uses of this approach include Garrod and Willis (1997) for non-use value of enhancing forest diversity; Georgiou et al. (2000) for the value of inner-city water quality improvement; Mackenzie (1993) for the value of hunting trips; and Garrod and Willis (1998) for amenity value for inland waterways. Other applications are summarized in Layton (1995); theoretical issues are explained in Hanemann and Kanninen (1999) and Train (2003).

In all cases presented here, the baseline alternative to which other yard designs were compared is the traditional lawn. The regressions resulting from this analysis can be used directly to estimate the probability that a person with specified characteristics will choose one of a set of two or more goods. WTP can then be estimated from the estimated equation by finding $\Delta C / \Delta E$ (where $\Delta E$ represents shifting from the traditional lawn to the alternative design) for the specific function used, the difference in price necessary to achieve a $50 \%$ probability that a person with average characteristics will purchase the good. At that probability, the person is equally likely to choose either option and is thus indifferent between the choices. The price that makes the person indifferent between the options is the maximum that she would pay for the more desirable option.

Details are provided in Appendix A. The regression analysis used $\operatorname{LIMDEP}^{\odot}$ 7.0.

\section{Survey design}

The survey was designed based on conditions in southeast Michigan, an area experiencing a great deal of housing development in exurban areas, typically on land that had been in agricultural production. As a result, the rivers of the area have seen deterioration in their biological integrity (Roth et al., 1996). Yard 
designs adopting native plants are rarely used. Landscape designers, homeowners, and local governments either may be unaware of more ecologically beneficial designs for yards, may dislike them, may not believe that these designs are marketable, or may face state or local ordinances that discourage the use of these designs.

This research is based on Nassauer's past research (Nassauer, 1992, 1993, 1995a,b, 1997, 2004) on the cultural sustainability of ecological design. According to this theory, ecologically beneficial landscape designs that also are valued for their appearance are more likely to exist over the long term in a human-dominated landscape. Using digital simulations depicting residential landscapes with varying degrees of these characteristics, Nassauer (1993) found that "care," "neatness," and "naturalness" were significant predictors for the attractiveness of landscape designs, some of which included native plants in residential yards.

In this research, respondents were asked to rate care, neatness, naturalness, attractiveness, and pride on 1-7 scale bipolar adjective scales (good care-poor care, neat-messy, and natural-artificial). ${ }^{3}$ Pride was included as a new perception variable to test the hypothesis that people preferred yards of which they were proud.

Both the landscape preference and contingent choice parts of the survey used three cases: two terrestrial front yards and one back yard on a shoreline. The two front yards, each with a different house, provided some idea of the role of the house in people's perceptions of the yards. The shoreline back yard was included partly because it is a very different setting from the other two, and partly because changing shoreline vegetation might have a more ecologically influential effect than changing terrestrial vegetation in a front yard.

This study follows Nassauer (1993) in using digital simulations for the design treatments to be studied. In each case (the two front yards and the back yard), the respondent was presented with four simulations showing different yards for the same house. The choices presented were: (1) traditional lawn, (2) $50 \%$ prairie garden, (3) $75 \%$ prairie garden, and (4) $75 \%$ prairie garden with additional native shrubs. Within these param-

\footnotetext{
3 To promote thoughtful answers, the inverse scale was used for attractiveness and care (i.e. 1 is the highest and 7 is the lowest). The order of the attributes was also randomized.
}

eters, each of the experimental treatments was designed to display the "cues to care" identified in past research (Nassauer, 1995), since attractive designs are likely to be the ones people would consider installing. The images for the two front yards were a subset of the images used in the 1993 study, while the images for the back yard were created for the current study using the same concepts as were used in the development of the previous images.

This study was intended to test whether the proportion of native plant garden areas in turf-dominated residential landscapes affected public perception because proportion of turf has been found to affect public perceptions (Nassauer, 1993; Gobster and Westphal, 2004; Ryan, 2000). It is widely known that native plants in metropolitan landscapes typically are perceived as messy and unattractive (Nassauer, 1995; Ryan, 1997; Barro and Bright, 1998; Gobster and Hull, 2000). To test for effect of proportion of native plant gardens, the experimental designs controlled for other design characteristics that could affect perceived attractiveness. Garden plant composition to emphasize flowers, clear views through to doors, mowing near the street-all of these "cues to care" were employed in all treatments used in this survey (Nassauer, 1997). Consequently, data could be used to test the theory of cultural sustainability by measuring whether landscapes that had ecological benefits and were designed to be attractive would indeed be perceived as attractive - so that people would be willing to pay more to have them.

This study is not designed to indicate that landscapes with native plants are superior to all landscapes that use more traditional plants. Rather, it can provide information on whether it is possible to design yards with native plants that people are willing to purchase.

Prices were estimated for each of the landscape designs by contacting professional landscape installation and maintenance firms in the southeast Michigan, the study area. They were asked to provide information on both the installation costs and the monthly maintenance costs; these are presented in Table 1. The installation costs were averaged on a per-month basis over 5 years and added to the maintenance cost to give an estimated monthly total cost. The ranges from the designers yielded a high and low estimate for each yard treatment. For the prices used as response items in the survey, the range of prices was further broadened to increase variety, and then sets of random prices from 
Table 1

Monthly cost of each yard

\begin{tabular}{lllll}
\hline Cost & $\begin{array}{l}\text { Typical lawn } \\
\text { (Yard A) }\end{array}$ & $\begin{array}{l}50 \% \text { Prairie } \\
\text { (Yard B) }\end{array}$ & $\begin{array}{l}\text { 75\% Prairie } \\
\text { (Yard C) }\end{array}$ & $\begin{array}{l}75 \% \text { Prairie plus } \\
\text { shrub (Yard D) }\end{array}$ \\
\hline Install range (turf) (\$) & $1400-2000$ & $1400-2000$ & $700-1000^{*}$ & $700-1000^{*}$ \\
Install range (prairie) (\$) & N/A & $2880-3000$ & $2880-3000$ & $3180-3300^{* *}$ \\
Maintenance range (\$) & $700-1000$ & $1000-1200$ & $700-1000$ & $700-1000$ \\
Minimum total cost, 5 years (\$) & 4900 & 9280 & 7080 & 7380 \\
Minimum average monthly cost over 5 years (\$) & 82 & 155 & 118 & 123 \\
Maximum total cost, 5 years (\$) & 7000 & 11,000 & 9000 & 9300 \\
Maximum average monthly cost over 5 years (\$) & 117 & 183 & 150 & 155 \\
Range used in survey (\$) & $75-130$ & $135-190$ & $110-158$ & $123-162$ \\
\hline
\end{tabular}

* These are based on 1 acre. Because the yard is less than 1 acre, this is a high estimate.

** Includes estimated shrub costs of $\$ 300$.

that range were generated. Different survey respondents saw one set of prices from several different sets of prices that were generated. ${ }^{4}$ As will be discussed further below, the range of prices is used to examine how people's choices are affected by the amount they would spend on the landscape.

Respondents were provided with following background information on the landscape designs.

These yards include different amounts of lawn, prairie garden, shrubs, and trees. The lawn is turf grass. If the yard is only lawn, then the trees and shrubs are non-native. The lawn may take 6 months to 1 year to become established.

The prairie garden consists of wildflowers and grasses with native shrubs and trees. The prairie garden attracts more wildlife than the lawn. If the yard has a prairie garden the trees and shrubs are native plants. The prairie garden may take up to 3 years to become established.

Maintenance of the lawn includes annual pruning of the trees and shrubs, autumn raking, weekly mowing of the lawn, and yearly fertilization. Maintenance of the prairie garden includes mowing the prairie garden every few years.

For each case, respondents faced four simulated photos of the same house seen with different lawn treatments on one page. In one part of the survey, they were then asked to rate the attributes; in another part, the

\footnotetext{
${ }^{4}$ As will be discussed further below, the survey was administered both in person, using paper surveys, and in a web-based form. For the paper survey, each respondent saw one of three different sets of prices; for the web survey, the prices presented were 1 of 20 sets of prices.
}

photo display included a monthly price associated with each, and respondents were asked to rank their choices of the yards.

Two issues must be discussed related to data collection. First, the survey was administered in two ways. It was initially designed to be presented to a live audience, with the photo simulations presented as a slide show and people filling out their responses on a paper form..$^{5}$ A total of 123 paper surveys were collected. Later, this survey was put onto a web site, with 314 respondents filling out their choices on the computer. ${ }^{6}$ (Total responses are 480, including 43 no-record data.) It is possible that responses might differ because of the different formats. These differences were explored and found not to be important statistically.

Second, this paper reports on the willingness-to-pay analysis that was only one aspect of the larger project

\footnotetext{
5 The target population for the larger project consisted of homeowners and people who were not homeowners but who were looking to buy a home now or within 5 years in the upper Midwest, who might be familiar with Midwestern residential landscapes such as those shown in the images. A targeted opportunity sample of this population was obtained for the paper version of the survey through cold calling of local community groups in southeast Michigan, such as churches, environmental organizations, and even a group of naturists.

${ }^{6}$ For the web survey, the targeted opportunity sample of this population was obtained via web links from news outlets and community web sites in southeast Michigan, email advertising to a statewide environmental electronic mail list server, and an informational article in the Ann Arbor, Michigan, local newspaper. This resulted in a respondent sample concentrated in southeast Michigan, but that also included scattered respondents throughout the state, several from other states in the upper Midwest, and a few from states outside the Midwest.
} 
Table 2

Demographic data for the sample

\begin{tabular}{|c|c|c|c|c|}
\hline Characteristic & Description & Yard sample & Total sample & Census \\
\hline Gender & $\%$ of male & 30.04 & 37.26 & 49.7 \\
\hline Property & $\%$ Homeowner & 92.65 & 85.56 & 57 \\
\hline Envgrp & $\%$ Belonging to an environmental group & 46.53 & 47.74 & NA \\
\hline Age & $\begin{array}{l}\text { Mean } \\
\text { Median }\end{array}$ & $\begin{array}{l}45.27 \\
45\end{array}$ & $\begin{array}{l}44.74 \\
44\end{array}$ & $\begin{array}{l}\text { NA } \\
31.3\end{array}$ \\
\hline Annual income & $\begin{array}{l}\text { Under } \$ 30,000 \\
\$ 30.000-49,999 \\
\$ 50,000-79,999 \\
\$ 80,000-119,999 \\
\$ 120,000-199,999 \\
\$ 200,000-349,999 \\
\text { Over } \$ 350,000\end{array}$ & $\begin{array}{l}3.74 \% \\
18.22 \% \\
28.97 \% \\
31.31 \% \\
13.08 \% \\
4.21 \% \\
0.47 \%\end{array}$ & $\begin{array}{l}6.08 \% \\
18.54 \% \\
27.96 \% \\
31.61 \% \\
12.46 \% \\
3.04 \% \\
0.03 \%\end{array}$ & $\begin{array}{l}27.68 \% \\
20.30 \% \\
23.61 \% \\
15.39 \% \\
9.60 \% \\
3.51 \%\end{array}$ \\
\hline Mean & $\$ 89,814$ & & & \\
\hline Education & $\begin{array}{l}\text { Elementary } \\
\text { Middle school } \\
\text { High school } \\
\text { Some college } \\
\text { Bachelors degree } \\
\text { Some graduate training } \\
\text { Graduate degree }\end{array}$ & $\begin{array}{l}0.00 \% \\
0.00 \% \\
2.09 \% \\
14.23 \% \\
31.80 \% \\
14.64 \% \\
37.24 \%\end{array}$ & $\begin{array}{l}0.00 \% \\
0.00 \% \\
3.05 \% \\
15.79 \% \\
30.47 \% \\
14.40 \% \\
36.29 \%\end{array}$ & $\begin{array}{l}2.39 \% \\
5.19 \% \\
17.26 \% \\
26.55 \% \\
24.57 \% \\
24.03 \%\end{array}$ \\
\hline
\end{tabular}

*Washtenaw county data were constructed from U.S. Census 2000.

goals for the survey, which required respondents from many different perspectives in order to understand the perspectives of the general public. In contrast, the most credible WTP estimates would be expected to come only from people who are likely to be facing the actual tradeoffs presented in the survey-that is, people in the market for installing a new yard design. Consequently, this economic analysis uses only a sub-sample of all survey respondents - those who were most likely to be in the market for or knowledgeable about making decisions about landscape designs for their yards, those who identified themselves as homeowners and tenants planning to buy a house within 5 years. As a result, the data set for the economic analysis included 245 respondents.

Table 2 provides demographic data for the whole sample (Total), the sub-sample used for the yard analysis (Yard), and for the population of Washtenaw County as a whole (Census). (Washtenaw County, whose largest city is Ann Arbor, was the center of the study.) It shows that the sample used for the yard analysis was more female, better educated, older, and wealthier than the average resident of Washtenaw County. Because it is likely that suburban and exurban homeowners are more educated, older, and wealthier than average residents, this sample may be more appropriate than a truly random sample of Washtenaw County residents.

For each case, the respondent ranked the digital simulations of the yard designs with their associated costs per month, expressed as an increase in cost relative to the traditional lawn. Thus, the dependent variable is a ranked choice among four alternatives, with the price difference between the traditional lawn and the alternative design as an independent variable.

\section{Results}

Two specifications were used in the final regression (see Tables 3-5). Specification I includes only price and choice dummies; II, an extended version of I, incorporates variables reflecting characteristics of individuals.

As previously described, Cases 1 and 2 are the two replicates of the street front yards; Case 3 is the shoreline back yard. Yard A is a conventional lawn, Yard B is $50 \%$ prairie garden, Yard C is $75 \%$ prairie garden, 
Table 3

Regression results for Case 1

\begin{tabular}{llc}
\hline Variable & I Coefficient & II Coefficient \\
\hline Price $(\$$ month $)$ & $-0.0122^{* * *}(-16.95)$ & $-0.0115^{* * *}(-5.02)$ \\
Envgrp $\times$ price $($ member $=1 ;$ no $=0)$ & & $0.0000(0.01)$ \\
Age $\times$ price & & $-0.0002(-1.64)$ \\
Gender $\times$ price $($ female $=1 ;$ male $=0)$ & & $-0.0008(-0.35)$ \\
Property $\times$ price $($ home owner $=1 ;$ no $=0)$ & & $0.0074(1.65)$ \\
Price/income $(\$ / 1000)$ & $1.4899^{* * *}(10.51)$ & $-0.0214^{* * * *}(-6.01)$ \\
A_B & $1.6854^{* * *}(11.92)$ & $1.4628^{* * *}(8.65)$ \\
A_C & $1.1485^{* * *}(7.97)$ & $1.6665^{* * *}(9.88)$ \\
A_D & -587.9959 & $1.2503^{* * *}(7.26)$ \\
Unrestricted log-likelihood & -648.6864 & -519.4119 \\
Restricted log-likelihood & 227 & -648.6864 \\
Number of observations & 121.3810 & 202 \\
Likelihood ratio test & 0.0936 & 258.5490 \\
Pseudo- $R^{2}$ & & 0.1993
\end{tabular}

The asymptotic $t$-values are in parentheses. Pseudo- $R^{2}=1-($ unrestricted log likelihood/restricted log likelihood).

*** Levels of statistical significance are $P<0.001$.

and Yard D is composed of $75 \%$ prairie garden plus additional native shrubs.

In all three cases, in both regression forms, all the price and yard dummy variables are statistically significant with the predicted signs, indicating that people are responsive to price and that they are willing to pay more for the alternative designs compared to the conventional lawn. Table 6 provides the change in willingness to pay relative to the conventional lawn for each case and each yard (details of the calculation are in the Appendix A). WTPs for each yard are robust across the specifications. In all cases, average WTP for the designs including prairie gardens is positive, suggesting that people are willing to pay a premium for these alternatives. The preference order for the yard types is C, B, D, A for Cases 1 and 2, and D, C, B, A for Case 3 . For the most part, Cases 1 and 2 show similar results, while the results for Case 3, the shoreline backyard, are different. The consistency of the results between Cases 1 and 2 suggests greater reliability in these findings for front yards; the results for Case 3 do not contradict the implications of these results for the desirability of prairie gardens, but they suggest that different settings may influence the details of the results.

Table 4

Regression results for Case 2

\begin{tabular}{lll}
\hline Variable & I Coefficient & II Coefficient \\
\hline Price $(\$ /$ month $)$ & $-0.0135^{* * *}(-18.31)$ & $-0.0209^{* * *}(-9.23)$ \\
Envgrp $\times$ price $($ member $=1 ;$ no $=0)$ & & $-0.0003(-0.14)$ \\
Age $\times$ price & & $0.0000(0.32)$ \\
Gender $\times$ price $($ female $=1 ;$ male $=0)$ & & $0.0040(1.68)$ \\
Property $\times$ price $($ home owner $=1 ;$ no $=0)$ & & $0.0020(0.48)$ \\
Price/income $(\$ 1000)$ & $1.7010^{* * *}(11.83)$ & $-0.0154^{* * *}(-4.95)$ \\
A_B & $1.7969^{* * *}(12.46)$ & $1.7166^{* * * *}(9.83)$ \\
A_C & $1.3011^{* * *}(8.71)$ & $1.8819^{* * * *}(10.79)$ \\
A_D & -561.9099 & $1.3856^{* * *}(7.75)$ \\
Unrestricted log-likelihood & -630.9831 & -489.0798 \\
Restricted log-likelihood & 227 & -630.9831 \\
Number of observations & 138.1464 & 201 \\
Likelihood ratio test & 0.1095 & 283.8066 \\
Pseudo- $R^{2}$ & & 0.2249 \\
\hline
\end{tabular}

The asymptotic $t$-values are in parentheses. Pseudo- $R^{2}=1-($ unrestricted log likelihood/restricted log likelihood).

**** Levels of statistical significance are $P<0.001$. 
Table 5

Regression results for Case 3

\begin{tabular}{lll}
\hline Variable & I Coefficient & II Coefficient \\
\hline Price $(\$$ month $)$ & $-0.0147^{* * * *}(-18.45)$ & $-0.0407^{* * *}(-15.44)$ \\
Envgrp $\times$ price $($ member $=1 ;$ no $=0)$ & & $0.0006(0.25)$ \\
Age $\times$ price & & $0.0000(-0.06)$ \\
Gender $\times$ price $($ female $=1 ;$ male $=0)$ & & $0.0044(1.72)$ \\
Property $\times$ price $($ home owner $=1 ;$ no $=0)$ & & $0.0232^{* * *}(4.94)$ \\
Price/income $(\$ 1000)$ & $1.5126^{* * *}(10.16)$ & $-0.0094^{* *}(-2.95)$ \\
A_B & $2.0315^{* * *}(13.59)$ & $1.5456^{* * * *}(8.29)$ \\
A_C & $2.1059^{* * *}(13.77)$ & $2.1178^{* * * *}(11.35)$ \\
A_D & -526.3843 & $2.2506^{* * * *}(11.67)$ \\
Unrestricted log-likelihood & -604.5438 & -447.8752 \\
Restricted log-likelihood & 224 & -604.5438 \\
Number of observations & 156.3190 & 198 \\
Likelihood ratio test & 0.1293 & 313.3372 \\
Pseudo- $R^{2}$ & & 0.2592
\end{tabular}

The asymptotic $t$-values are in parentheses. Pseudo- $R^{2}=1-($ unrestricted log likelihood/restricted log likelihood).

${ }^{* *}$ Levels of statistical significance are $P<0.01$.

*** Levels of statistical significance are $P<0.001$.

Regression II includes a range of demographic variables that might influence WTP. Only the coefficient of price/income is statistically significant (along with a variable identifying property owners for Case 3 ). As the monthly cost increases as a fraction of income, the likelihood of an individual preferring that alternative decreases. In other words, income levels matter in willingness to pay for these alternative designs.

The coefficient of envgrp $\times$ price is not significant in any of the regressions: in other words, environmental group membership does not appear to affect

Table 6

WTP per house (\$/month)

\begin{tabular}{llll}
\hline Case & Variable & Model I & Model II \\
\hline 1 & B over A & $122.01^{* * * *}(17.42)$ & $113.06^{* * *}(17.46)$ \\
& C over A & $138.02^{* * *}(18.23)$ & $128.80^{* * * *}(18.28)$ \\
& D over A & $94.05^{* * *}(16.02)$ & $96.63^{* * *}(16.35)$ \\
2 & B over A & $126.09^{* * *}(16.14)$ & $114.91^{* * *}(15.21)$ \\
& C over A & $133.20^{* * *}(16.61)$ & $125.98^{* * *}(15.93)$ \\
& D over A & $96.45^{* * *}(15.20)$ & $92.76^{* * *}(14.74)$ \\
3 & B over A & $102.90^{* * *}(14.60)$ & $95.13^{* * *}(14.36)$ \\
& C over A & $138.20^{* * *}(16.38)$ & $130.35^{* * *}(16.11)$ \\
& D over A & $143.26^{* * *}(16.64)$ & $138.52^{* * *}(16.60)$ \\
\hline
\end{tabular}

Refer to Appendix A for details of calculation of WTP. Standard errors are shown in parentheses. The asymptotic variances of WTP were estimated by the delta method based on a truncated Taylor series expansion. Refer to Hanemann and Kanninen (1999), pp. 334-336 for details.

${ }^{* * * *}$ Levels of statistical significance are $P<0.001$.
WTP. In contrast, Nassauer (1993) found that ecological knowledge affects people's perception values, using environmental group membership as a proxy for ecological knowledge. The lack of statistical significance here may suggest that more ecological knowledge is not directly related to higher WTP. This finding is consistent with a study of yard chemical use in San Francisco (Templeton et al., 1999). In this study, environmental group membership substantially increased the probability of chemical use (on average about 1.7 times). The authors suggest that "members of environmental organizations enjoy nuisance pest reductions, better looking yards, or more productive gardens more than others because, in spite of possibly stronger concerns about chemical runoff and exposure, they value outdoor environments more and take more precautions than others." They also refer to a similar result in Seattle and all other parts of King County, Washington from 1992 to 1994, which found that "the percentage of households that used pesticides increased most among those with the most 'pro-environment' attitudes and behaviors" (DDI, 1995, cited in Templeton et al., 1999).

From a policy perspective, as discussed above, the ability of private markets to provide these ecologically beneficial results depends on whether individuals' WTP exceeds the costs of installing and maintaining these yard designs. Table 7 compares the range of WTP estimates to the range of cost estimates for the yard designs. Net WTP (WTP less cost) is positive in all but 
Table 7

Net WTP increase (\$/month)

\begin{tabular}{|c|c|c|c|}
\hline Yard & Case 1 & Case 2 & Case 3 \\
\hline \multicolumn{4}{|l|}{$\mathrm{B}$} \\
\hline Range of WTP increase over A (\$) & $113-122$ & $115-126$ & $95-103$ \\
\hline Range of cost increase ${ }^{\mathrm{a}}(\$)$ & $2-101$ & $2-101$ & $2-101$ \\
\hline Range of net $\mathrm{WTP}^{\mathrm{b}}(\$)$ & $12-120$ & $14-124$ & $-6-101$ \\
\hline \multicolumn{4}{|l|}{$\mathrm{C}$} \\
\hline Range of WTP increase over A (\$) & $129-138$ & $126-133$ & $130-138$ \\
\hline Range of cost increase ${ }^{\mathrm{a}}(\$)$ & $1-74$ & $1-74$ & $1-74$ \\
\hline Range of net $\mathrm{WTP}^{\mathrm{b}}(\$)$ & $55-137$ & $52-132$ & $56-137$ \\
\hline \multicolumn{4}{|l|}{$\mathrm{D}$} \\
\hline Range of WTP increase over A (\$) & 94-97 & $93-96$ & 139-143 \\
\hline Range of cost increase ${ }^{a}(\$)$ & $6-73$ & $6-73$ & $6-73$ \\
\hline Range of net $\mathrm{WTP}^{\mathrm{b}}(\$)$ & $21-91$ & $20-90$ & $66-137$ \\
\hline
\end{tabular}

a The maximum value is calculated from Table 1 as the difference between the maximum cost for the alternative design and the minimum cost for the lawn; the minimum value uses the minimum cost for the alternative design and the maximum cost for the lawn.

b The maximum is the maximum WTP less the minimum cost; the minimum is the minimum WTP less the maximum cost.

one case, where the minimum estimated WTP is compared to the maximum cost estimate; in that case, the estimated range for net WTP is very large, and most of the range is positive. For Cases 1 and 2, net WTP for Yard C (75\% prairie garden) is highest, whereas net WTP for Yard D (75\% prairie garden plus native shrubs) is highest for Case 3 (shoreline back yard).

Some qualifications are appropriate for these results. Because the alternative landscape designs are marketable goods, a typical economic assumption is that, if people are willing to pay for them, they should appear on the market. Nevertheless, they are not in common use. It is reasonable to wonder whether the results presented here do not actually reflect consumer desires, or whether there are currently obstacles to the market availability of these designs. One possible reason that the results here may not reflect actual behavior is, as discussed earlier in this paper, hypothetical bias- the tendency of people to overstate their willingness to pay for a good in hypothetical situations. If people respond with hypothetical bias, then the results here may overestimate people's willingness to pay for these designs. Among possible reasons that there may be obstacles to their introduction include local ordinances or subdivision rules that limit the kinds of plantings used in yards, or lack of understanding about the installation and maintenance of these designs, or lack of native plants in the wholesale and retail nursery trade. While the results presented here should not be considered absolute evidence of the marketability of these landscapes, they are suggestive that homeowners may respond positively to marketing of these landscapes.

\section{Conclusion}

This paper estimated willingness to pay for yard designs with ecological characteristics superior to those of a standard lawn. While previous research has shown that these yards can be designed to be esthetically pleasing, this study extends those results to show that people are willing to pay a premium for these designs as well. It is thus possible for private markets to provide ecological improvements, without policy intervention, in the absence of policies that restrict the use of these designs and in the presence of landscape designers knowledgeable about these designs. In some cases, institutional barriers (such as homeowners' association rules or local ordinances) may limit the use of these designs; in these cases, government or association action may be necessary to permit these landscapes. When landscape designers are not knowledgeable about these designs, there may be a role either for new entrants to the market, for greater training in these designs in landscape architecture programs, or for extension work from universities to designers to demonstrate these possibilities.

The desirability of these yards in general may in part be due to the fact that the prairie garden simulations used in this study were specifically designed 
to be esthetically pleasing. Though on first blush this approach may appear to be "stacking the deck" in favor of these designs, in fact it helps to demonstrate that careful design can lead to popular acceptance of ecologically beneficial yard patterns.

Nevertheless, the results here highlight the importance of setting for these results. The differences in results between Cases 1 and 2 (the terrestrial front yards) and Case 3 (the shoreline back yard) suggests that responses to these landscapes depend on their physical context.

Finally, it is important to repeat some of the limitations of this study. It was conducted based on simulations specifically appropriate for southeast Michigan (that is, using plantings appropriate for this setting), and the population sampled in this research was not carefully targeted toward those in the market for new yards (because of the mixed objectives of the different parts of the survey instrument). Additionally, because it is based on hypothetical scenarios, there may be some tendency for respondents to overstate their willingness to pay. While the results presented here cannot be considered to apply generally to use of native plantings in other parts of the world (or even the U.S.), the consistency and statistical power of the WTP results does suggest a willingness on the part of many people in the upper Midwest of the U.S. for the adoption of more ecologically beneficial yard designs.

\section{Acknowledgments}

Funding for this project was provided by the Water and Watersheds Program (NSF DEB-9900697) and the University of Michigan's Office of the Vice President for Research. The authors wish to thank Tim Maull and Daniel Blake for their research assistance on this project, and David Allan for the collaboration on the larger-scale project.

\section{Appendix A. Calculation of willingness to pay (WTP)}

As discussed in the text, the calculation of WTP for each yard type was based on two different regression models, here called I and II. Model I, the simplest, only includes price and dummy variables that represent the different yards compared to the baseline, the traditional lawn. Model II adds demographic variables interacted with price as explanatory variables.

Section II of the paper describes the theory behind the WTP calculations. The specific calculations are: in model I,

$$
\mathrm{WTP}=\frac{\Delta C}{\Delta E}=-\frac{\text { coefficient on yard dummy }}{\text { coefficient on price }}
$$

In model II,

$$
\begin{aligned}
\mathrm{WTP}= & \frac{\Delta C}{\Delta E} \\
=- & \frac{\text { coefficient on yard dummy }}{\text { [coefficient on price }+ \text { (coefficient }} \\
& \text { on price/income }) / \text { income } \\
& +\sum(\text { coefficients on characteristics } \\
& \quad \times \text { characteristics values })]
\end{aligned}
$$

In model II, WTP depends on income and personal characteristics of individuals. Average WTP is estimated by using the average income and characteristics of the relevant population. As described in the paper, the calculations developed here use the means from the sample used in the analysis, on the basis that the sample is more representative of the relevant population than using mean population characteristics for Washtenaw County, the study site. These values are in Table 2.

\section{References}

Barro, S.C., Bright, A.D., 1998. Public views on ecological restoration: a snapshop from the Chicago Area. Restoration Manage Notes 16 (1), 59-65.

Beggs, S., Cardell, S., Hausman, J., 1981. Assessing the potential demand for electric cars. J. Econometrics 16, 1-19.

Bormann, F.H., Balmori, D., Geballe, G.T., 1993. Redesigning the American Lawn: A Search for Environmental Harmony. Yale University Press, New Haven, CT, pp. 86-117 (Chapter 6).

Diekelmann, J., Schuster, R., 2002. Natural Landscaping: Designing with native plant communities, second ed. The University of Wisconsin Press, Madison, WI.

Diamond, P.A., Hausman, J.A., 1994. Contingent valuation: is some number better than no number? J. Econ. Perspect. 8 (Fall), 45-64.

Freeman III, A.M., 1993. The Measurement of Environmental and Resource Values: Theory and Methods. Resources for the Future, Washington, DC. 
Garrod, G.D., Willis, K.G., 1997. The non-use benefits of enhancing forest biodiversity: a contingent ranking study. Ecol. Econ. 21, $45-61$.

Garrod, G.D., Willis, K.G., 1998. Using contingent ranking to estimate the loss of amenity value for inland waterways from public utility service structure. Environ. Resource Econ. 12, 241-247.

Georgiou, S., Bateman, I., Cole M., Hadley, D., 2000. Contingent ranking and valuation of river water quality improvements: testing for scope sensitivity, ordering and distance decay effects. CSERGE Working Paper GEC 2000-18. UK.

Gobster, P.H., Hull, R.B., 2000. Restoring Nature: Perspectives from the Social Sciences and Humanities. Island Press, Washington, DC.

Gobster, P.H., Westphal, L.M., 2004. The human dimensions of urban greenways: planning for recreation and related experiences. Landscape Urban Plann. 68 (2-3), 147-165.

Hanemann, W.M., Kanninen, B., 1999. The statistical analysis of discrete-response CV data. In: Bateman, I.J., Willis, K.G. (Eds.), Valuing Environmental Preferences. Oxford University Press, New York, pp. 302-441.

Lareau, T.J., Rae, D.A., 1989. Valuing WTP for diesel odor reductions: an application of contingent ranking technique. Southern Econ. J. 55 (3), 728-742.

Layton, D.F., 1995. Specifying and Testing Econometric Models for Stated Preference Surveys. PhD Dissertation, Department of Economics, University of Washington, Seattle.

List, J.A., 2001. Do explicit warnings eliminate the hypothetical bias in elicitation procedures? Evidence from field auctions for sports cards. Amer. Econ. Rev. 91 (5), 1498-1507.

List, J.A., Berrens, R.P., Bohara, A.K., Kerkvliet, J., 2004. Examining the role of social isolation on stated preferences. Amer. Econ. Rev. 94 (3), 741-752.

List, J.A., Shogren, J.F., 2002. Calibration of willingness-to-accept. J. Environ. Econ. Manage. 43, 219-233.

Loomis, J., Helfand, G., 2001. Environmental Policy Analysis for Decision Making. Kluwer Academic Publishers, Boston.

Mackenzie, J., 1993. A comparison of contingent preference models. Am. J. Agr. Econ. 75, 593-603.

Nassauer, J.I., 1992. The appearance of ecological systems as a matter of policy. Landscape Ecol. 6, 239-250.

Nassauer, J.I., 1993. Ecological function and the perception of suburban residential landscapes, in: Gobster, P.H. (Ed.), Managing Urban and High-Use Recreation Settings, General Technical
Report, USDA Forest Service, North Central Forest Experimental Station, St. Paul, MN, pp. 55-60.

Nassauer, J.I., 1995a. Culture and changing landscape structure. Landscape Ecol. 10 (4), 229-237.

Nassauer, J.I., 1995b. Messy ecosystems, orderly frames. Landscape J. 14, 161-170.

Nassauer, J.I., 1997. Cultural sustainability: aligning aesthetics and ecology. In: Nassauer (Ed.), Placing Nature: Culture and Landscape Ecology. Island Press, Washington, DC, pp. 65-83.

Nassauer, J.I., 2004. Monitoring the success of metropolitan wetland restorations: cultural sustainability and ecological function. Wetlands 24 (4).

Northeastern Illinois Planning Commission, 1998. Natural Landscaping Toolkit, US Environmental Protection Agency, Region 5, Chicago, IL.

Roth, N.E., Allan, J.D., Erickson, D., 1996. Landscape influences on stream biotic integrity assessed at multiple scales. Landscape Ecol. 11, 141-156.

Ryan, R.L., 1997. Attachment to urban natural areas: effects of environmental experience. Dissertation. Natural Resources and Environment, University of Michigan.

Ryan, R.L., 2000. A people-centered approach to designing and managing restoration projects: insights from understanding attachment to urban natural areas. In: Gobster, P.H., Hull, R.B. (Eds.), Restoring Nature. Island Press, Washington, DC, pp. 209-226.

Templeton, S.R., Yoo, S.J., Zilberman, D., 1999. An economic analysis of yard care and synthetic chemical use: the case of San Francisco. Environ. Resource Econ. 14, 385-397.

Train, K.E., 2003. Discrete choice methods with simulation. Cambridge University Press, New York.

Gloria E. Helfand is associate professor of environmental economics in the School of Natural Resources and Environment at the University of Michigan.

Joon Sik Park is a PhD student in the School of Natural Resources and Environment at the University of Michigan.

Joan I. Nassauer is professor of landscape architecture in the School of Natural Resources and Environment at the University of Michigan.

Sandra Kosek received her $\mathrm{PhD}$ from the School of Natural Resources and Environment at the University of Michigan, with a specialization in landscape architecture. 